\title{
Maternal vitamin D levels in hypertensive disorders of pregnancy
}

\author{
Vatika Tyagi*, Mamta Tyagi, Smriti Gupta, Esha Khanuja, Yamini Varma
}

Department of Obstetrics and Gynaecology, Subharti Medical College, Meerut, Uttar Pradesh, India

Received: 14 October 2020

Revised: 26 October 2020

Accepted: 27 October 2020

\section{*Correspondence:}

Dr. Vatika Tyagi,

E-mail: tyagivatika@gmail.com

Copyright: ( ) the author(s), publisher and licensee Medip Academy. This is an open-access article distributed under the terms of the Creative Commons Attribution Non-Commercial License, which permits unrestricted non-commercial use, distribution, and reproduction in any medium, provided the original work is properly cited.

\section{ABSTRACT}

Background: Current study was conducted with the objective to evaluate maternal vitamin D levels in patients with hypertensive disorders of pregnancy.

Methods: The present prospective observational study was conducted among 200 pregnant women attending gynaecological OPD of Subharti medical college, Meerut, over a period of two years and satisfying the inclusion criteria were enrolled. On admission, patient demographic profile, complete history was recorded, and comprehensive clinical examination was done. In all the patients, blood samples for routine examination along with LFT, RFT, random blood sugar, serum electrolytes, serum uric acid and serum vitamin D were drawn, and serum levels of these biochemical parameters were determined according to standard laboratory procedures. Subjects were classified into three categories according to serum vitamin D level i.e. $>20 \mathrm{ng} / \mathrm{ml}$ (mild), 10-20 ng/ml (moderate deficiency), <10 $\mathrm{ng} / \mathrm{ml}$ (severe deficiency).

Results: Insignificant difference was found between case (hypertensive) and control (normotensive) group when compared in relation to age, education, parity and socioeconomic status. The mean vitamin D level of women with HDP was $5.7 \pm 2.99 \mathrm{ng} / \mathrm{ml}$ as compared to $17.34 \pm 5.79 \mathrm{ng} / \mathrm{ml}$ in normotensive women with statistically significant difference as $\mathrm{p}<0.001$. No correlation was found between severity of vitamin $\mathrm{D}$ deficiency and maternal complications $(\mathrm{p}=0.318)$.

Conclusions: The results of the present study concluded that women with hypertension had significantly lower vitamin D level as compared to normotensive women.

Keywords: Vitamin D, Hypertensive disorders, Pregnancy, Preeclampsia

\section{INTRODUCTION}

Vitamin D (sunshine vitamin) has been studied as a potentially modifiable factor contributing to extra skeletal health during pregnancy. ${ }^{1}$ Vitamin $\mathrm{D}$ deficiency is worldwide epidemic, with a prevalence that ranges from $18 \%$ to $84 \%$ depending on the country of residence, ethnicity, and local clothing customs and dietary intake..$^{1-3}$ Hypertension is the most common medical problem encountered during pregnancy complicating 5-10\% of pregnancies. ${ }^{4}$ Maternal vitamin D metabolism is altered during pregnancy, leading to increased circulating levels of both the vitamin D binding protein (VDBP) and the active metabolite, 1,25-dihydroxyvitamin D $\left(1,25(\mathrm{OH})_{2} \mathrm{D}\right)$. Clinical studies establishing an association between vitamin D levels and adverse pregnancy outcomes such as preeclampsia, gestational diabetes, and low birth weight, preterm labor, and caesarean delivery have conflicting results. Data is sparse as regards the prevalence of vitamin $\mathrm{D}$ deficiency during pregnancy in India is concerned. ${ }^{5}$

\section{Aim and objectives}

The purpose of current study was to investigate the association of vitamin $\mathrm{D}$ and risk of hypertensive 
disorders in pregnancy and maternal vitamin $\mathrm{D}$ levels in patients with hypertensive disorders of pregnancy.

\section{METHODS}

Current study was a prospective observational study and was conducted in the department of obstetrics and gynaecology, Chhatrapati Shivaji Subharti hospital, Subharti Medical College, Meerut, Uttar Pradesh. Between November 2018 to August 2020 with a sample size of 100 case and 100 control subjects. One hundred patients with hypertensive disorders of pregnancy and satisfying the inclusion criteria were enrolled and profiled as a part of this study.

\section{Sample size}

Sample size was taken as 100 cases and 100 control subjects. The sample was calculated on the basis of prevalence using the formula;

$N=(\mathrm{Z} 1-\alpha / 2+\mathrm{Z}-\beta) 2 \times(\mathrm{s} 12+\mathrm{s} 22) /(\mathrm{A}-\mathrm{B})^{2}$

Where, the mean serum vitamin D level was 9.06 \pm 5.20 $\mathrm{ng} / \mathrm{ml}$ in the diseased group compared to $13.67 \pm 7.24$ $\mathrm{ng} / \mathrm{ml}$ in the healthy pregnant group. ${ }^{1}$

At $95 \%$ confidence level and $80 \%$ power of the study, patients of hypertensive disorders of pregnancy and nonpregnant women (sample size) required to conduct such a new comparative study were calculated. Sample size was calculated to be 200 (100 cases and 100 controls). The software (statistical tool) used was SPSS 23.0

\section{Inclusion and exclusion criteria}

All pregnant women with hypertensive disorders admitted to Subharti hospital in the mention term were included in the study. All pregnant women with multifetal gestation, epilepsy, bone disorders, any multivitamin intake, renal disease, liver disease, hemorrhagic disorders, thyroid disease or any endocrinal disease. Patients would have to meet the American college of obstetricians and gynaecology (ACOG) criteria for diagnosing hypertensive disorders of pregnancy.

\section{Control group}

The control group in this study was one hundred normotensive pregnant women with similar gestational age.

\section{Procedure}

Patients would have to meet the American college of obstetricians and gynaecology (ACOG) criteria for diagnosing hypertensive disorders of pregnancy (diastolic blood pressure $\geq 90 \mathrm{mmHg}$ or systolic blood pressure $\geq 140 \mathrm{mmHg}$ or both). Vein puncture technique was used to collect fasting blood samples. Quantitation of serum
$25(\mathrm{OH})$ vitamin D [25(OH) D2 plus 25(OH) D3] was performed using the chemiluscence method by Centaur $\mathrm{XP}$ in the biochemistry laboratory of Subharti medical college, Meerut. This method can detect $25(\mathrm{OH})$ vitamin $\mathrm{D}$ in the range of $4.2-150 \mathrm{ng} / \mathrm{ml}$. Calcium was measured by the use of the O-cresolphthalein complex using dimension by RXL. Parathormone was measured using chemiluminometric technology by Centaur XP. PTH assay was a 2-site sandwich immunoassay. Serum samples were drawn at similar gestational ages in both groups.

\section{Screening/survey}

A total of 110 women were screened, 7 were rejected to participate in the study and 3 were not fit according to inclusion criteria and finally, 100 women with hypertensive disorders during pregnancy were found fit according to inclusion criteria.

\section{Quality control measure to check data completeness and consistency}

Local and English language was preferred to ask the screening questions during the initial screening of patients with valid identity proof and also recorded the data. Study tools used were, case reporting forms and consent forms. After written informed consent form had been obtained, detailed history of the presenting symptoms and their onset was recorded. Detailed histories of all the women were obtained (like demographic, age of the patient, parity, last menstrual period, previous menstrual history) were noted on patient proforma. Each participant underwent an ultrasonographic examination to estimate the gestational age, routine haemogram, and other biochemical investigations were carried out as and when required.

\section{Confounders}

Present demonstration of hypertensive disorders of pregnancy was defined by diastolic Blood pressure $\geq 90$ $\mathrm{mmHg}$ or systolic blood pressure $\geq 140 \mathrm{mmHg}$ or both. The detailed history of women included; age, religion, literacy, occupation, residence, the socioeconomic status will be noted. Obstetrics history, past history, any history of previous pregnancy affected by HDP, family history, pre-existing medical conditions, gestational age, education, socioeconomic status and prenatal information.

\section{Outcome variables}

The outcome variables in current study were; to compare the maternal serum Vitamin D levels in patients with hypertensive disorders of pregnancy and normotensive women and to compare the maternal and neonatal outcome in these patients. 


\section{RESULTS}

In the present study, 200 women were included. One hundred women who had hypertensive disorders of pregnancy were included as "cases" group and the other hundred women without any hypertensive disorders. Demographic details of both the groups are shown in (Table 1).

Table 1: Demographic details of study groups.

\begin{tabular}{|c|c|c|}
\hline \multirow[b]{2}{*}{ Demographic details } & \multicolumn{2}{|c|}{ Groups $(n=200)$} \\
\hline & $\begin{array}{l}\text { Case } \\
(n=100)\end{array}$ & $\begin{array}{l}\text { Control } \\
(n=100)\end{array}$ \\
\hline \multicolumn{3}{|l|}{ Age (years), N (\%) } \\
\hline $19-25$ & $59(59.0)$ & $64(64.0)$ \\
\hline $26-31$ & $31(31.0)$ & $30(30.0)$ \\
\hline $31-37$ & $7(7.0)$ & $5(5.0)$ \\
\hline$>37$ & $3(3.0)$ & $1(1.0)$ \\
\hline \multicolumn{3}{|c|}{ Area of residence, $\mathbf{N}(\%)$} \\
\hline Urban & $58(58.0)$ & $70(70.0)$ \\
\hline Rural & $42(42.0)$ & $30(30.0)$ \\
\hline \multicolumn{3}{|c|}{ Employment status, N (\%) } \\
\hline Employed & $43(43.0)$ & $49(49.0)$ \\
\hline Unemployed & $57(57.0)$ & $51(51.0)$ \\
\hline \multicolumn{3}{|l|}{ Education, N (\%) } \\
\hline Illiterate & $26(26.0)$ & $23(23.0)$ \\
\hline Literate & $55(55.0)$ & $51(51.0)$ \\
\hline $\begin{array}{l}\text { Graduation/post } \\
\text { graduation }\end{array}$ & $19(19.0)$ & $26(26.0)$ \\
\hline \multicolumn{3}{|c|}{ Socioeconomic status, N (\%) } \\
\hline Upper & $1(1)$ & $3(3)$ \\
\hline Upper middle & $36(36)$ & $47(47)$ \\
\hline Lower middle & $32(32)$ & $34(34)$ \\
\hline Lower & $31(31)$ & $16(16)$ \\
\hline \multicolumn{3}{|l|}{ Gravida status, N (\%) } \\
\hline Primigravida & $71(71)$ & $76(76)$ \\
\hline Multigravida & $29(29)$ & $24(24)$ \\
\hline
\end{tabular}

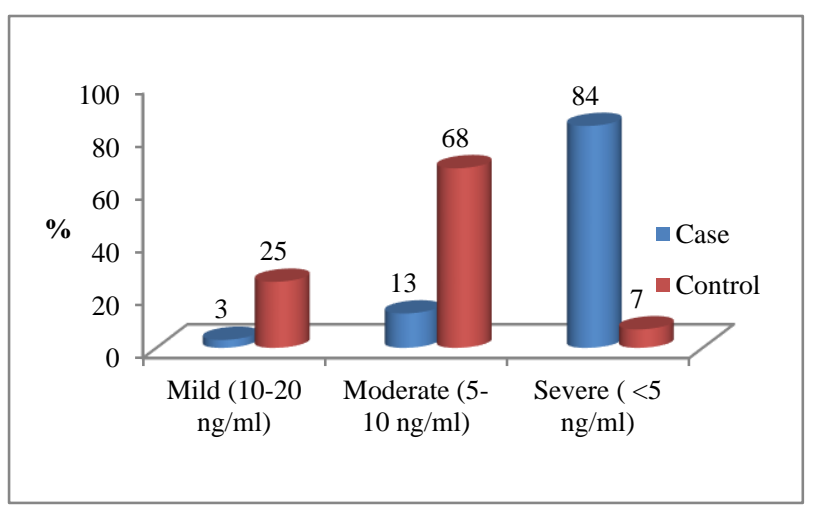

Figure 1: Distribution of patients on the basis of vitamin D level.

The sub-classification of women on the basis of type of hypertensive disorders of pregnancy was done and the majority of women i.e. $43.0 \%$ had preeclampsia, $28.0 \%$ had gestational hypertension and $19.0 \%$ had chronic hypertension while only $10.0 \%$ women had chronic hypertension with superimposed preeclampsia.Serum vitamin D was determined for every participant. The mean vitamin D level of women with HDP was $5.7 \pm 2.99$ $\mathrm{ng} / \mathrm{ml}$ as compared to $17.34 \pm 5.79 \mathrm{ng} / \mathrm{ml}$ in normotensive women. This difference was statistically significant with $\mathrm{p}<0.001$.

Majority of women (84\%) in hypertensive group had severe vitamin D deficiency as compared to $13 \%$ with moderate and $3 \%$ with mild deficiency of vitamin $D$. The difference among two groups was statistically significant $(\mathrm{p}<0.001)$. Whereas among normotensive women only $4 \%$ had severe vitamin D deficiency, $68 \%$ had moderate deficiency and $25 \%$ had mild deficiency of vitamin $\mathrm{D}$.

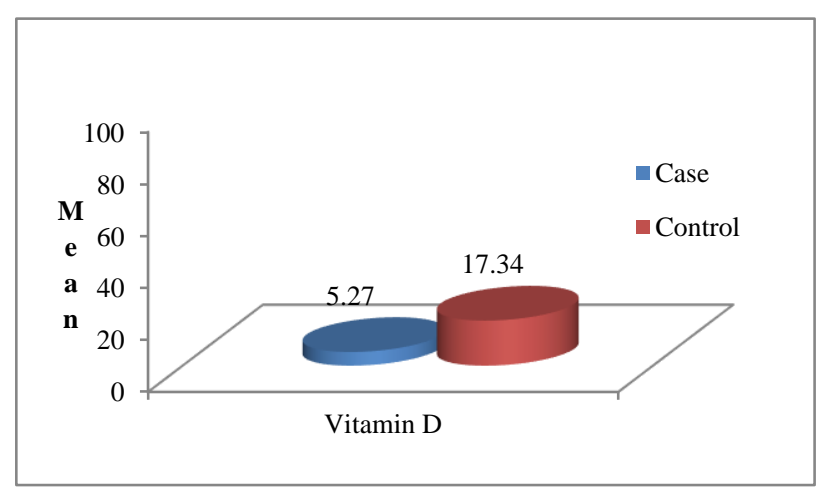

Figure 2: Mean vitamin D levels in cases and controls.

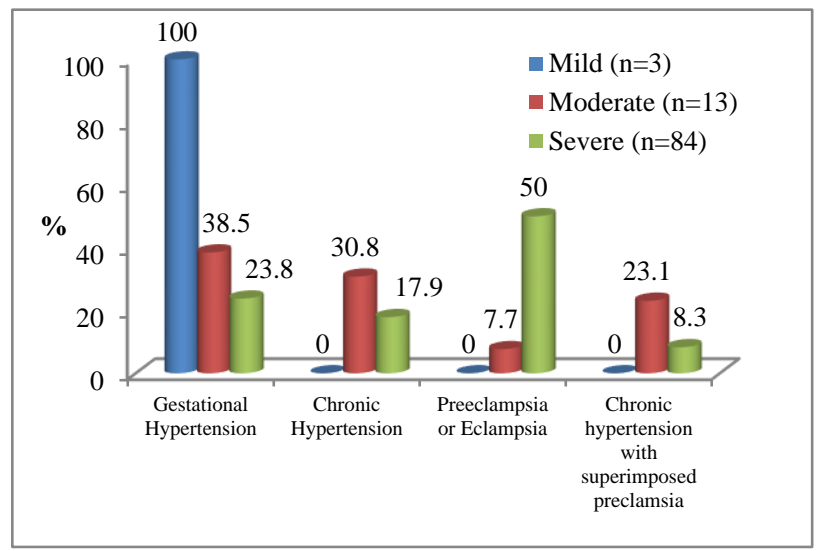

Figure 3: Association of vitamin D deficiency with type of hypertension.

Women were classified according to ACOG guidelines in the "cases" group and studied association of severity of vitamin D deficiency with type of hypertensive disorder. It was observed that all women with mild vitamin D deficiency had gestational hypertension. Among women with moderate deficiency of vitamin $\mathrm{D}, 38.5 \%$ had gestational hypertension, $30.8 \%$ had chronic hypertension. Among women with severe vitamin D deficiency, majority (i.e. 42\%) had preeclampsia followed by gestational hypertension (23.8\%) and 
chronic hypertension (17.9\%). Though it appeared that women with vitamin D deficiency had increased incidence of preeclampsia as compared to mild/ moderate deficiency, the data showed the difference to be statistically insignificant $(\mathrm{p}=0.009)$.

In group containing women with hypertensive disorders of pregnancy, eclampsia was in majority $(30.2 \%)$ followed by HELLP syndrome $(27.9 \%)$ and pulmonary edema (16.3\%).

No correlation was found between severity of vitamin D deficiency and maternal complications ( $p=0.318)$. In study population, 36\% neonates had low Apgar at 1 minute and $27 \%$ had low Apgar at 5 minutes. $41 \%$ neonates required NICU admission, 62\% developed hyperbilirubinemia, $45 \%$ had respiratory disease and $17 \%$ neonates were born premature.

\section{DISCUSSION}

Sahu et al conducted a similar study where the mean serum vitamin D level was $9.06 \pm 5.20 \mathrm{ng} / \mathrm{ml}$ in diseased group as compared to $13.67 \pm 7.24 \mathrm{ng} / \mathrm{ml}$ in healthy pregnant group which was statistically significant $(p<0.05)$ and exactly similar to the present study. ${ }^{6}$ Mehta et al conducted a study also concluded vitamin $\mathrm{D}$ level is lower in women with HDP as compared to healthy pregnancy women also the level of vitamin D decreases with severity of HDP. ${ }^{7}$ Similar to current study, Gupta et al found more incidence of severe vitamin D deficiency $(90 \%)$ in preeclamptic patients as compared to normotensive patients $(62 \%) .^{8}$

In current study it was found that no women in hypertensive as well as normotensive group had normal serum vitamin D levels, all had same degree of vitamin D deficiency indicating the high prevalence of vitamin $\mathrm{D}$ deficiency in India.

Women, who had hypertensive disorders of pregnancy, had significantly lower serum vitamin D levels as compared to normotensive pregnant ladies. Though severity of vitamin D deficiency did not show any correlation with type of hypertensive disorder of pregnancy or maternal or neonatal complications.

\section{CONCLUSION}

There was no statistical significant difference between the demographic data of cases and control. Incidence of vitamin $\mathrm{D}$ deficiency was found more in patients with hypertensive disorders of pregnancy. No correlation was found between severity of vitamin D deficiency and maternal as well as neonatal complications.

Funding: No funding sources

Conflict of interest: None declared

Ethical approval: The study was approved by the Institutional Ethics Committee

\section{REFERENCES}

1. Institute of medicine (us) committee to review dietary reference intakes for vitamin D and Calcium. In: Ross AC, Taylor CL, Yaktine AL, Del Valle HB, eds. Dietary Reference Intakes for Calcium and Vitamin D. Washington (DC): National Academies Press (US); 2011.

2. Ponsonby AL, Lucas RM, Lewis S, and Halliday J. Vitamin D status during pregnancy and aspects of offspring health. Nutrients. 2010;2(3):389-407.

3. Sharma S, Kumar A, Prasad S, and Sharma S. Current scenario of vitamin $d$ status during pregnancy in North Indian population. J Obstet Gynecol India. 2016;66(2):93-100.

4. Berhan Y. No hypertensive disorder of pregnancy; no preeclampsia- eclampsia; no gestational hypertension; no hellp syndrome. Vascular disorder of pregnancy speaks for all. Ethiop J Health Sci. 2016;26(2):177-86.

5. Goel P, Garg G, Kaur J, MehraR, Tandon R, Huria A. Association of vitamin $\mathrm{D}$ deficiency during pregnancy with preeclampsia and eclampsia. Int $\mathbf{J}$ Reprod Contracept Obstet Gynecol. 2016;5:3046-50.

6. Sahu M, Tripathy S, Bhuyan P. Association of maternal serum vitamin D level with preeclampsia or eclampsia and its relationship with neonatal outcome and neonatal serum calcium level. Int $\mathbf{J}$ Reprod Contracept Obstet Gynecol. 2017;6:5580-6.

7. Mehta S, Mahala M, Sharma M. Maternal vitamin D levels in hypertensive disorder of pregnancy and healthy pregnant women. IOSR J Dent Med Sci. 2016;15(6):86-8.

8. Gupta T, Wahi S, Gupta N, Arora S, Gupta S, Bhatia P. Correlation of vitamin D levels in term normotensive and pre-eclamptic patients in labor. J Obstet Gynaecol India. 2016;66(3):154-9.

Cite this article as: Tyagi V, Tyagi M, Gupta S, Khanuja E, Varma Y. Maternal vitamin D levels in hypertensive disorders of pregnancy. Int J Reprod Contracept Obstet Gynecol 2020;9:4870-3. 